\title{
Uses of barium meal examination in dyspeptic patients under 50
}

\author{
G M MEAD, A MORRIS, G K WEBSTER, M J S LANGMAN
}

British Medical fournal, 1977, 1, 1460-1461

\section{Summary}

No abnormality was found in 76 of 100 dyspeptic outpatients under the age of 50 who underwent barium meal examination, while various non-malignant lesions were found in the remaining 24 . Only $10 \%$ of those under 30 , and $10 \%$ of those with symptoms for less than a year proved to have any abnormality. Because of the radiographic results treatment was altered in only 11 patients, and most of these changes were small.

\section{Introduction}

Dyspepsia and other upper gartrointestinal complaints are common in young and middle-aged patients but rarely reflect serious underlying disease. Most such patients are treated symptomatically and investigated no further, but a proportion are referred either directly from the general practitioner or via the outpatient department for a barium meal examination. It is our clinical impression that the result of the $x$-ray examination, normal or abnormal, seldom alters the management of these patients. We therefore sought to confirm or deny this impression by determining the frequency of abnormal findings in dyspeptic outpatients aged under 50 and comparing the treatment given before and after the examination.

\section{Patients and methods}

One hundred outpatients aged under 50 with dyspeptic symptoms were examined, 68 patients being referred directly by their general practitioners and 32 coming from the outpatient department.

A consultant radiologist interviewed all patients before radiography and obtained answers to a standard questionnaire about the duration and severity of dyspepsia and its treatment. To minimise the chances of investigation altering the pattern of management we deliberately chose not to inform referring doctors of our study.

At least three months later we wrote to the referring doctor to obtain details of management before and after radiography. Hospital notes were examined to obtain this information for patients referred from the outpatient department.

City Hospital, Nottingham NG5 1PB

G M MEAD, MB, MRCP, medical registrar

A MORRIS, MB, FRCR, consultant radiologist

G K WEBSTER, MB, MRCP, medical registrar

M J S LANGMAN, MD, FRCP, professor of therapeutics, University of Nottingham

\section{Results}

Altogether we studied 63 men and 37 women, aged from 15 to 49 . The result of the barium meal examination was abnormal in 24 . Sixteen patients had evidence of present or past ulceration of the upper gastrointestinal tract, and none had any evidence of cancer (table I).

The following factors influenced the chances of detecting abnormalities.

TABLE I-Findings and their site in 24 abnormal barium meal examinations

\begin{tabular}{|c|c|c|c|}
\hline Stomach and duodenum & $\begin{array}{c}\text { No of } \\
\text { patients }\end{array}$ & Oesophagus & $\begin{array}{c}\text { No of } \\
\text { patients }\end{array}$ \\
\hline $\begin{array}{l}\text { Gastric ulcer } \\
\text { Gastric and duodenal ulcer } \\
\text { Duodenal ulcer } \\
\text { Scarred duodenum } \\
\text { Gastroenterostomy and scarred } \\
\text { duodenum } \\
\text { Duodenal diverticulum }\end{array}$ & $\begin{array}{l}1 \\
1 \\
8 \\
5 \\
1 \\
1\end{array}$ & $\begin{array}{l}\text { Oesophagitis } \\
\text { Oesophageal reflex } \\
\text { Hiatus hernia }\end{array}$ & $\begin{array}{l}1 \\
2 \\
4\end{array}$ \\
\hline
\end{tabular}

Characteristics of symptoms-Eighty-six of the patients complained of dyspeptic symptoms, 36 of nausea or vomiting, and 27 of weight loss. A few had symptoms referable to the oesophagus, eight with heartburn, and seven with dysphagia. No differences were noted in the overall patterns in those with radiological abnormalities and those without.

Duration of complaint-Only four $(9.3 \%)$ out of 43 patients with symptoms of less than a year's duration proved to have any detectable radiological abnormality compared with $20(35.1 \%)$ of the remaining 57 (table II).

Age of patients-Three $(10.3 \%)$ of 29 patients under 30 had detectable abnormalities compared with $21(29.6 \%)$ of 71 aged from 30 to 50 .

TABLE II-Duration of symptoms in the 100 patients studied

\begin{tabular}{c|c|c}
\hline $\begin{array}{c}\text { Duration of symptoms } \\
\text { (years) }\end{array}$ & $\begin{array}{c}\text { Normal radiograph } \\
(\mathrm{n}=76)\end{array}$ & $\begin{array}{c}\text { Abnormal radiograph } \\
(\mathrm{n}=24)\end{array}$ \\
\hline$<-1$ & 39 & 4 \\
$1-5$ & 25 & 9 \\
$>5$ & 12 & 11 \\
\hline
\end{tabular}

FURTHER INVESTIGATION

In all, 11 patients were examined in more detail by endoscopy, cholecystography, chest radiography, or electrocardiography (table III). Additional abnormalities were discovered in two, one patient proving to have a gastric ulcer and one to have gall stones.

Six of the 68 patients who had been investigated by their general practitioners were referred to hospital: three were referred with normal and three with abnormal findings. Three were subsequently discharged symptom-free without further investigation, one who proved 
TABLE III-Further investigation in patients studied

\begin{tabular}{|c|c|c|c|}
\hline \multirow{2}{*}{$\begin{array}{c}\text { Further } \\
\text { investigation }\end{array}$} & \multicolumn{3}{|r|}{ Initial radiology } \\
\hline & Normal $(n=7$ & & Abnormal $(n=4)$ \\
\hline Endoscopy & $\begin{array}{l}\text { Normal } \\
\text { Gastric ulcer }\end{array}$ & & $\begin{array}{l}\text { Duodenal ulcer-confirmed } \\
\text { Gastroduodenoscopy-normal endoscopy } \\
\text { Prepyloric ulcer-defaulted }\end{array}$ \\
\hline Cholecystography & $\begin{array}{l}\text { Gall stones } \\
\text { Normal }\end{array}$ & $\begin{array}{l}1 \\
2\end{array}$ & Hiatus hernia-no gall stones found \\
\hline $\begin{array}{l}\text { Electrocardiography } \\
\text { and chest radio- } \\
\text { graphy }\end{array}$ & Normal & 1 & \\
\hline
\end{tabular}

to have gall stones underwent cholecystectomy, a fifth was discharged after proving to have a normal cholecystogram, and a sixth was discharged after endoscopy had also shown no abnormality.

\section{EFFECT OF FINDINGS UPON DRUG TREATMENT}

Ninety-one patients were taking antacids, 28 received anticholinergic drugs, and nine a liquorice preparation before referral for radiology. Only six of the 76 who had normal findings had some change in their treatment. Two were given anticholinergic agents and one an anxiolytic drug, while the remaining three had treatment stopped.

Of the 24 with abnormal findings, one with a hiatus hernia was given chlordiazepoxide and two with duodenal ulcer were given liquorice preparations. None of the others had their drug treatment changed.

\section{OVERALL EFFECTS OF INVESTIGATION ON MANAGEMENT}

Apart from changes in drug treatment in nine patients there were clear changes of management in only two others. One, who after a normal barium meal examination underwent cholecystography, proved to have gall stones and was operated on. The other, who was also operated on, was a man aged 48 who had radiological evidence of gastric and duodenal ulceration. Barium meal examination nine years previously had shown duodenal ulceration, and he had then refused surgery. Nine of the total group (seven with normal and two with abnormal radiographs) failed to attend to discover the results of their examinations.

\section{Discussion}

Dyspeptic symptoms are common, and peptic ulceration is the most prevalent identifiable cause of such complaints. Many patients with upper abdominal symptoms who are examined radiologically or endoscopically prove, however, to have no abnormality. In north-east Scotland, where duodenal ulcer is probably twice as common as in England, ${ }^{2} 29 \%$ of people questioned during a general-practice survey proved to have troublesome dyspepsia, and $8 \%$ of the total group had current radiological or other evidence of peptic ulceration. ${ }^{3}$ Again in north-east Scotland half of all barium meal examinations showed abnormalities of the oesophagus, stomach, or duodenum. ${ }^{2}$ This apparently high proportion of abnormal findings does not help in deciding the value of examination. The critical points are whether the findings influence treatment and whether these findings tend to occur more often in any special age or symptom group.

The incidence of gastric ulcer increases with age and duodenal ulcer is now beginning to follow the same pattern. ${ }^{1}{ }^{4}$ The frequency of gastric cancer likewise increases with age, following a logarithmic curve so that in men, who have incidence rates that are about twice those of women, the disease is 40 times commoner in those aged 60 to 65 than in those aged 30 to $35 .{ }^{5}$ Therefore the chances of finding important disease decrease greatly in younger patients. We chose an arbitrary age limit of 50 for our study; but a decision about when investigation will be useful is an individual one. Some guidance may, however, be derived from the findings.

Only $10^{\circ}{ }_{0}$ of our patients under the age of 30 proved to have any detectable abnormality, and in none of these was treatment substantially altered by the findings. Likewise, only $10 \%$ of patients with symptoms present for less than a year proved to have any abnormality, and again none of these had any important change in treatment. If radiology served any purpose it was likely to be as a treatment itself in reassuring the patient, though if this were so, it is surprising that drug treatment was seldom modified or stopped after radiographs were found to be normal. In this context it was discouraging to find that nearly $10 \%$ of patients failed to return to discover the result of the examination: the fact that 69 of the 76 patients who had normal barium meal results were not investigated further also suggests to us that few of them had important and persistent symptoms.

In most young patients conventional treatment with antacids and advice to take small frequent meals and stop smoking is associated with symptomatic remission, and an exact diagnosis adds nothing. In those with persistent symptoms radiology or endoscopy is justified because specific treatments with liquorice derivatives or the histamine $\mathrm{H}_{2}$ antagonist cimetidine can then reasonably be administered to those in whom ulcer disease is found. A careful history taken at the first visit can also do much to exclude those with functional dyspepsia from further investigation and find those at particular risk of severe disease such as cancer. $^{6}$

We are grateful to our colleagues for their willing help in completing this survey.

\section{References}

${ }^{1}$ Brown, R C, Langman, M J S, and Lambert, $\mathrm{P}$ M, British Medical fournal, 1976, 1, 35.

Petrie, J C, Needham, C D, and Gillanders, L A, British Medical fournal, 1972, 2, 78.

${ }^{3}$ Weir, R D, and Backett, G M, Gut, 1968, 9, 75

4 Susser, M, Fournal of Chronic Diseases, 1967, 20, 439.

Doll, R, Payne, P, and Waterhouse, J A H, Cancer Incidence in Five Continents. Berlin, Springer Verlag, 1966.

${ }^{6}$ Horrocks, J C, and de Dombal, F T, British Medical fournal, 1975, 3, 421.

(Accepted 25 March 1977)

Does intermenstrual pain occur in women taking the combined contraceptive pill?

Intermenstrual is a word suggesting only certain time relationships, so, of course, intermenstrual pain may occur in the cases mentioned. But the implied question is whether the pill could be the cause of pain, and this is unlikely. Ovulation pain (mittelschmerz) is possible, for in some women breakthrough ovulation can occur rarely, though again pain from this cause is unlikely. Any continuing or recurrent pain needs full and careful analysis and should not be too readily attributed to some postulated side effect of the pill, lightly to be dismissed.

An unmarried woman of 31 has a younger sister who has muscular dystrophy of the Duchenne's type. Though healthy, the patient is worried that, if she marries, any children might be affected. Her.parents are first cousins, but there is no other family history of the disease on either side. What are the chances of her children being affected?

Since it is a sister who is affected and the parents are first cousins the muscular dystrophy is probably of the autosomal recessive limb-girdle type, rather than one of the two $\mathrm{X}$-linked types. With recessive inheritance the risk to the inquirer's children would be low, provided that she is not marrying a first cousin. A neurologist's opinion on the sister's disease to confirm that it conforms to recessive limb-girdle type rather than the X-linked Duchenne or Becker types would be helpful. 